\title{
A Research for Measuring Administrative Effectiveness
}

\author{
Mehmet Durdu Karsli ${ }^{1}$ and Sevilay Sahin ${ }^{2}$ \\ ${ }^{1}$ Department of Educational Administration, Faculty of Education, \\ Eastern Mediterranean University, Turkey \\ ${ }^{2}$ Department of Educational Sciences, Faculty of Education, Gaziantep University, Turkey
}

KEYWORDS Management. Effectiveness Criteria. Organizational Level. Knowledge Workers and Characteristics of Effective Universities

ABSTRACT The purpose of this research is to develop an instrument for the evaluation of administrative effectiveness, by discussing the aspects of organizational effectiveness and organizational levels in a university. The sample of the research consisted of 203 academic personnel as the study group of the research. The results of the study indicated that university organizations can be evaluated through administrative effectiveness criteria that are developed by synthesizing four levels into organizational structure of the universities. The results of the study also showed that there is a fifth level at policy-strategy level and a study which is conducted without considering this aspect will be insufficient. The results also revealed that evaluation tool for administrative effectiveness which is developed to that end and be used in administrative effectiveness research and studies in universities.

\section{INTRODUCTION}

Although many studies have been conducted, only some of them have focused on administrative actions and behaviors. This kind of researches have introduced intuitions and ideas about formal and informal elements of the administrative duties, allocation of time among these duties, interpersonal interaction network, basic subjects of characteristics of administrative duties (Steward 1989). This relationship was noticed by a rarely applied research trend and examined delicately. This trend dealt with the actions and behaviors of managers to measure the effectiveness (Cammock et al. 1995).

The concept of administrative effectiveness has been defined differently by different authors due to its complex nature (Bao 2009). Some researchers defined it as "administrative effectiveness is the positive response to administrative efforts and actions with the intention to accomplish stated goal (Akomolafe 2012; Ademilua 2012). Although, administrative effectiveness is defined as the product of a series of complex

Address for Correspondence:

Dr. Mehmet Durdu Karsli,

Department of Educational Administration,

Faculty of Education,

Eastern Mediterranean University,

Famagusta, North Cyprus via Mersin 10 Turkey

Telephone: +903926304044

Fax: +903926304038

E-mail: mehmet.karsli@emu.edu.tr nested relations and an interaction pattern (Cammock et al. 1995).

An administration's capacity to forecast problems beforehand shows itself as a result of the characteristics and behaviors in his personal relationships and consulting criteria. In leading a group, the concept of leadership is regarded as effectiveness (Adeniyi and Omoteso 2014). Effective administration requires a balance of skills among many dimensions (Cammock et al. 1995) and these dimensions and parameters are influenced to a different degree by personal, organizational, and environmental contextual factors (Analoui 2007). This balance includes not only a series of quality behaviors but also many personality traits as an administrator.

Organizational size is another contingency variable which is thought to affect the effectiveness of different organizational forms (Hofler 2010). Small organizations can behave informally while larger organizations tend to become more formalized. The owner of a small organization may directly control most of the organizational processes, but large organizations require more complex and indirect control mechanisms. Large organizations can have more specialized staff, units, and jobs (Amah et al. 2013).

Organizational development is regarded as improving the organizational effectiveness and defined as the process of preparing and managing the change in an organization (Gibson et al. 1994). Based on this definition, organizational development is considered as an administrative technique or tool to complete main changes in 
an organization. Organizational development as an administrative technique fulfills real administrative values without regard to the values of means of change. Thus, organizational development is evaluated in an ethical frame and regarded as an ethical concept (Garza 1991). Administrators can perform organizational development in a number of ways. This is because managing the change includes very important and non-ignorable ethical matters. Additionally, administrators can use various approaches to manage the planned change (Lovelady 1994).

In an organization, the knowledge worker is the production factor that makes highly developed societies and economies, such as the United States of America, Western Europe, Japan and some other countries. These countries keep up their competitive edge maintaining their status simultaneously. The real fortune of the US that gives the country a competitive advantage is education. Education itself is something that offers tremendous advantage. Thus, knowledge workers become productive. For a knowledge worker, productivity is the ability to have the right things carried out. This is the administrative effectiveness itself (Drucker 1994).

Every knowledge worker employed in a modern organization is an administrator because s/ he displays actions that affect their organization positively or negatively. Someone in this kind of a position must make his/her own decisions. He or she cannot be the person who is following the orders only. Such person must take responsibility for his/her own contribution. This person can be deactivated, relieved of his/her powers or dismissed. However, as soon as s/he has a job, his/ her goals, standards and contribution are under his/her own supervision.

Whether a knowledge worker is an administrator, does not depend on whether s/he administers people. The knowledge work cannot be defined in terms of figures, money and cost. It can only be defined with its results. Furthermore, the structure of the group and size of administrative staff are not that determinative. This is because the authority of knowledge is effective as much as the authority of position (Drucker 1994).

Universities are the organizations with the highest number of knowledge workers and these organizations are actually complex systems. Complex systems are divided into power levels hierarchically (Miller 1978). In organizations, these levels are defined as individual, group, intergroup and organizational levels (Rousseau 1985; Staw 1984). This kind of typology of organizational levels is common in works and studies on organizational behavior and organizational development.

A model developed by Rashford and Coglan (1987) regarding the organizational levels is recommended to harmonize four different behavior levels in a systematic manner and to cover them together. In this model, organizational levels are determined as individual, face-to-face team, group-divisional and policy-strategy.

The study by Rashford and Coglan suggests that effectiveness of university administration can be maintained by using four levels of organizational behavior (individual, team, group-division, policy and strategy) or organizational behavior levels in a university, because these levels are important and critical for effective administration.

Effectiveness within the scope of organizational behavior is defined as the optimal relationship among productivity, quality, effectiveness, flexibility, satisfaction, competitiveness and development (Gibson et al. 1994). The field of organizational behavior defines three levels of analysis. These are individual, group and organization (Gibson et al. 1994, Rashford and Coglan 1992). Accordingly, these analysis levels determine three levels of administrative responsibility. These are effectiveness of individuals, effectiveness of groups and effectiveness of organizations (Gibson et al. 1994).

Determination of administrative effectiveness criteria may be useful in the evaluation of university administration by combining four aspects of organizational effectiveness (adaptation, goal attainment, integration, and creating and sustaining original values) and four organizational levels of the university (individual, team, group-divisional and policy-strategy).

\section{Aim}

The purpose of this research is to develop an instrument for the evaluation of administrative effectiveness, by discussing the aspects of organizational effectiveness and organizational levels in a university.

To achieve this purpose, the following research questions guided the study: 
1. What are the anticipated effectiveness criteria for each organizational level in a university?

2. To what extent are the criteria determined for each organizational level associated with the aspects of organizational effectiveness?

\section{Importance of the Research}

The evaluation of effectiveness depends on its purpose and the area of effectiveness (Miles 1979). This research will contribute to existing knowledge by defining the areas of administrative effectiveness in a university in line with administrative objectives.

In modern society, the focus of attraction has shifted towards the knowledge workers in these organizations. Those who know how to use knowledge, theory and conceptual thinking can become effective as much as they contribute to the organization. What makes the knowledge work effective is to focus on achieving the set goals of an organization. It is impossible to supervise knowledge workers directly or thoroughly. They can only be assisted. They must guide themselves to increase their performance and achieve efficiency (Drucker 1994). With this research, it is expected to offer useful insight and guidance to universities where knowledge workers are densely populated.

Apparent organizational characteristics of higher education institutions pose special problems for researchers in selecting the criteria of organizational effectiveness and evaluating such criteria. By this reason, just like the problems related to the concept of organizational effectiveness, the characteristics of institutions operate as obstacles in evaluating the effectiveness of universities and higher education institutions in an empirical manner. The researchers could not be reached any research directly related with this context in the literature for measuring administrative effectiveness in higher education institutions directly. Although there are implications and theories about the administrative effectiveness of universities or higher education institutions, there is no research encountered directly on administrative effectiveness. Thus, the results of this research will be a guild for future researches.

\section{MATERIAL AND METHODS}

This is a descriptive research with a survey prepared for literature review and evaluation of effectiveness criteria in order to develop an instrument for measuring administrative effectiveness.

\section{Population and Sample}

Population of the research consists of all academic staff working at faculties and vocational high schools of Abant Izzet Baysal University.

The research is conducted on the entire population, without sampling. However, not all population has been reached because some of them were on sick leave or abroad. Only 203 of 315 academic personnel could be reached (see Table 1 ). Thus, they are the study group of the research.

Table 1: Breakdown of the population and study group

\begin{tabular}{lrc}
\hline Academic title & Total & Contacted \\
\hline Professor & 23 & 16 \\
Associate Professor & 7 & 6 \\
Assistant Professor & 38 & 28 \\
Research Associate & 105 & 62 \\
Instructor & 100 & 55 \\
Lecturer & 34 & 29 \\
Expert & 8 & 7 \\
\hline Total & 315 & 203 \\
\hline
\end{tabular}

\section{Data Collection}

The data was gathered in four stages. In the first stage, researches on organizational and administrative effectiveness in the literature were reviewed, and then effectiveness criteria used in these researches were determined and listed.

In the second stage, all determined criteria were arranged in the form of judgment and an inventory with 200 items was created. This inventory was given to experts in the fields of educational administration and measurement and evaluation in education to determine the content validity, and necessary adjustments were made based on the opinions and recommendations of these experts.

In the third stage, the reliability of prepared inventory was tested in 50-person pilot group every 15 days by using test-retest method (see Table 2). 
In the final stage, 32 draft items which are inoperative according to the test-retest results were excluded, and 168-item inventory was administered personally by the researcher to the sample group between the dates December 10, 2012 and January 20, 2013, and data collection was completed on February 30, 2013. After that, reliability coefficient of the data collection tool was calculated as $(\mathrm{a}=.8910)$.

\section{Analysis of Data}

The data were analyzed in three stages.

In the first stage, inventories were numbered, the answers of subjects were grouped and coded and made ready for processing.

In the second stage, the coded data were entered in "SPSS (Statistical Package for Social Sciences) for Windows", and refined and made ready for analysis.

Finally, the data were analyzed using SPSS. In the analysis of data, factor analysis was used. The following actions were made in sequence in the analysis of data.
The items were subjected to factor analysis and their distribution to suitable factors was determined.

\section{FINDINGS AND DISCUSSION}

Research findings and comments about them are given in two sub-headings, namely the findings about the demographic characteristics of subjects and the findings about the sub-problem. Findings related to demographic characteristics are given in Table 1. The results of analysis that determine the distribution of items by factors and their relations are given and discussed (Table 2).

Table 2: Test-retest correlation

\begin{tabular}{|c|c|c|c|}
\hline Variable & $N$ & $\begin{array}{l}\text { Arithmetic } \\
\text { mean }\end{array}$ & $\begin{array}{l}\text { Standard } \\
\text { deviation }\end{array}$ \\
\hline Pretest & 50 & 165.8700 & 41.5213 \\
\hline Posttest & 50 & 165.3200 & 41.6014 \\
\hline Correlation & 50 & $r=.8680$ & \\
\hline
\end{tabular}

The results of factor analysis which shows to what extend the effectiveness criteria deter-

Table 3: Factor analysis on the aspects of organizational effectiveness at individual level

\begin{tabular}{|c|c|c|c|c|c|}
\hline \multirow[t]{2}{*}{ Aspects } & \multirow[t]{2}{*}{ Items } & \multicolumn{3}{|c|}{ Factors } & \multirow[b]{2}{*}{ Factor 4} \\
\hline & & Factor 1 & Factor 2 & Factor 3 & \\
\hline \multirow{13}{*}{$\begin{array}{l}\text { Creating and sustaining the } \\
\text { values system }\end{array}$} & 6 & .73793 & .24633 & .16852 & -.07962 \\
\hline & 4 & .72888 & .30507 & .05499 & .10835 \\
\hline & 1 & .72290 & .22768 & .21166 & -.12072 \\
\hline & 15 & .71233 & .14417 & -.00197 & .15348 \\
\hline & 5 & .69766 & .20909 & .16349 & .15903 \\
\hline & 2 & .67897 & .38338 & 19671 & -.01380 \\
\hline & 8 & .64852 & .31533 & .00492 & .09612 \\
\hline & 7 & .64394 & .15370 & .29199 & .01213 \\
\hline & 14 & .59635 & .16772 & .31486 & .18541 \\
\hline & 17 & .56846 & .40173 & .44414 & .02420 \\
\hline & 9 & .55781 & .34205 & .39538 & .04991 \\
\hline & 16 & .52675 & .43157 & .34520 & -.01992 \\
\hline & 3 & .45699 & .43442 & .32236 & -.19114 \\
\hline \multirow[t]{5}{*}{ Goal attainment } & 27 & .38847 & .77425 & .09359 & -.01663 \\
\hline & 20 & .12155 & .73963 & .01857 & .13015 \\
\hline & 18 & .29694 & .67362 & .36245 & .05605 \\
\hline & 26 & .52027 & .54557 & .09648 & .09499 \\
\hline & 28 & .45429 & .53770 & .25676 & -.13985 \\
\hline \multirow[t]{6}{*}{ Integration } & 13 & .07775 & -.13061 & .79187 & .03132 \\
\hline & 12 & .05931 & .15842 & .68919 & .01441 \\
\hline & 10 & .18547 & .08857 & .68003 & .06438 \\
\hline & 9 & .29820 & .14888 & .56407 & .33407 \\
\hline & 11 & .45159 & .25111 & .51501 & .11823 \\
\hline & 21 & .45362 & .27508 & .49258 & .13767 \\
\hline \multirow{8}{*}{ Adaptation } & 22 & .12091 & .18176 & -.11688 & .80513 \\
\hline & 24 & .25302 & .14034 & .15754 & .73088 \\
\hline & 30 & -.03766 & .00412 & .14549 & .69578 \\
\hline & 23 & .27159 & .02230 & .31103 & .66022 \\
\hline & 25 & .34749 & .02916 & .10664 & .63752 \\
\hline & 19 & .05628 & .12397 & .25665 & .42695 \\
\hline & Variance (\%) & 40.4 & 7.4 & 5.9 & 4.3 \\
\hline & Eigen values & 12.1 & 2.2 & 1.7 & 1.3 \\
\hline
\end{tabular}


mined for "individual level", the first organizational level in an university, are associated with the aspects of organizational effectiveness, and the distribution of items by aspects are given in Tables 3 and 4.

Table 4: Factor transformation matrix at individual level

\begin{tabular}{lrrrr}
\hline & Factor 1 & Factor 2 & Factor 3 & Factor 4 \\
\hline Factor 1 & .71545 & .56630 & .39096 & .12073 \\
Factor 2 & -.05051 & -.52080 & .85202 & -.01691 \\
Factor 3 & -.41166 & .23903 & .13894 & .86839 \\
Factor 4 & .56224 & -.59239 & -.31924 & .48067 \\
\hline
\end{tabular}

As it is seen in the tables, effectiveness criteria determined at individual level are grouped in four factors. This result supports previous researches about the four aspects of organizational effectiveness (see, for instance, Hoy and Miskel 1987). The result also sustained recent studies on the positive behavioral statements of managerial effectiveness (Wang 2011).

In the factor analysis on effectiveness criteria at individual level, the items above .45 are taken into account. Although loading of item 19 is .42 , it is included there, because individual level is the most concentrated level among other factors.

According to Factor Analysis on the Aspects of Organizational Effectiveness at Individual Level, items about fourth aspect (creating and sustaining the values system), second aspect (goal attainment), third aspect (integration) and first aspect (adaptation) of organizational effectiveness are covered under the first factor, second factor, third factor and fourth factor, respectively. Percentage of variance of these items are calculated as follows; 40, .04 in the first factor, 7 , .04 in the second factor, 5, .09 in the third factor, and 4- .03 in the fourth factor. Eigen values are found as follows; 12.1 in the first factor, 2.2 in the second factor, 1.7 in the third factor and 1.3 in the fourth factor.

According to the Correlation of the factors, the first factor is correlated positively with itself and second factor with the third factor, while the third factor is correlated positively and most densely with the fourth factor that is negatively correlated with the second factor. The result that the factors are correlated with each other in this way can be interpreted as another expression of proper distribution of items to factors.

The results of factor analysis which shows the extent to which the effectiveness criteria de- termined for "team level”, the second organizational level in an university, are associated with the aspects of organizational effectiveness, and the distribution of items by aspects are given.

As it can be seen in the Tables 5 and 6, effectiveness criteria determined at team level are grouped in four factors. These results are similar with the results of previous researches about the team level which is one of the levels in a university (Cameron 1978).

In the factor analysis on effectiveness criteria at team level, the items above .53 are taken into account. The fact that the results are considerably high degree is regarded significant in terms of internal consistency of items. As displayed in tables, items about the second aspect (goal attainment), the fourth aspect (creating and sustaining the values system), third aspect (integration) and first aspect (adaptation) of organizational effectiveness are covered under the first factor, second factor, third factor and fourth factor, respectively. Percentage of variance of these items are calculated as follows; $68.5 \%$ in the first factor, $4.4 \%$ in the second factor, $3.8 \%$ in the third factor, and $2.6 \%$ in the fourth factor. Eigen values are found as follows; 18.4 in the first factor, 1.1 in the second factor, 1.0 in the third factor and .6 in the fourth factor.

According to correlation of factors at the team level, the first factor is correlated positively with itself and second factor with the fourth factor, while the fourth factor is correlated positively and most densely with the with the third factor, and the third factor is negatively correlated with the second factor. The result that the factors are correlated with each other in this way can be interpreted as another expression of proper distribution of items to factors.

The results of factor analysis implied the extent to which the effectiveness criteria determined for "group-divisional level of university", the third organizational level at a university in Turkey, are associated with the aspects of organizational effectiveness, and the distribution of items by aspects are given.

As it can be seen in the Tables 7 and 8, effectiveness criteria determined at group-divisional level of university are grouped in four factors. This supports the results of previous researches about the university group-divisional level which is one of the levels in a university (Rashford and Coglan 1992). 
Table 5: Factor analysis on the aspects of organizational effectiveness at team level

\begin{tabular}{|c|c|c|c|c|c|}
\hline \multirow[t]{2}{*}{ Aspects } & \multirow[t]{2}{*}{ Items } & \multicolumn{4}{|c|}{ Factors } \\
\hline & & Factor 1 & Factor 2 & Factor 3 & Factor 4 \\
\hline \multirow[t]{10}{*}{ Goal attainment } & 24 & .84879 & .35967 & . 15829 & .12567 \\
\hline & 26 & .81949 & .39248 & .10379 & .15745 \\
\hline & 25 & .81653 & .37590 & 11990 & .20664 \\
\hline & 23 & .80319 & .38521 & .19550 & .15322 \\
\hline & 22 & .78352 & .46293 & 14609 & .20662 \\
\hline & 27 & .73729 & .31607 & .31569 & .12497 \\
\hline & 19 & .70702 & .47253 & .29412 & .02802 \\
\hline & 20 & .66590 & .49748 & 26779 & .08624 \\
\hline & 18 & .64985 & .51878 & .31690 & .08091 \\
\hline & 10 & .60425 & .55405 & .17479 & .21935 \\
\hline \multirow{12}{*}{$\begin{array}{l}\text { Creating and sust } \\
\text { values system }\end{array}$} & & & & & \\
\hline & 4 & .29913 & .81287 & .02413 & .24097 \\
\hline & 7 & .32520 & .79942 & .08044 & .16990 \\
\hline & 2 & .41989 & .70574 & .18625 & -.04435 \\
\hline & 8 & .34805 & .69925 & 40859 & .08497 \\
\hline & 6 & .47424 & .69035 & .07112 & .27228 \\
\hline & 5 & .51235 & .68087 & 19772 & .13439 \\
\hline & 13 & .42846 & .65770 & .29687 & .17755 \\
\hline & 3 & .45626 & .64460 & .25068 & .22365 \\
\hline & 17 & .52233 & .63815 & .32713 & .12111 \\
\hline & 11 & .55171 & .63760 & .14302 & .14018 \\
\hline & 16 & .55152 & .59743 & .34263 & .07144 \\
\hline \multirow[t]{4}{*}{ Integration } & 9 & .22172 & .14127 & .70370 & .56789 \\
\hline & 12 & .42136 & .22922 & .69918 & .15386 \\
\hline & 15 & .47614 & .37881 & .55525 & -.09127 \\
\hline & 14 & .32764 & .03847 & .53915 & .53645 \\
\hline \multirow[t]{4}{*}{ Adaptation } & 1 & .15519 & .23224 & .06605 & .89070 \\
\hline & 21 & .22732 & .07081 & .55087 & .68565 \\
\hline & Variance (\%) & 68.5 & 4.4 & 3.8 & 2.6 \\
\hline & Eigen values & 18.4 & 1.1 & 1.0 & .6 \\
\hline
\end{tabular}

Table 6: Factor transformation matrix at team level

\begin{tabular}{lrrrr}
\hline & Factor 1 & Factor 2 & Factor 3 & Factor 4 \\
\hline Factor 1 & .67815 & .65215 & .28444 & .18415 \\
Factor 2 & -.53940 & .30274 & .08626 & .78100 \\
Factor 3 & .41358 & -.69439 & .26585 & .52545 \\
Factor 4 & -.27950 & -.02945 & .91705 & -.28290 \\
\hline
\end{tabular}

In the factor analysis on effectiveness criteria at university group-divisional level, the items above .50 are taken into account. Although the loadings of the items 13 and 18 are lower than this level, they are included in the first factor. According to tables, items about the third aspect (integration), the second aspect (goal attainment), fourth aspect (creating and sustaining the values system) and first aspect (adaptation) of organizational effectiveness are covered under the first factor, second factor, third factor and fourth factor, respectively. Percentage of variance of these items are calculated as follows; $52.4 \%$ in the first factor, $4.9 \%$ in the second factor, and $4.0 \%$ in the third and fourth factors. Eigen values are found as follows; 19.9 in the first factor, 1.8 in the second factor, and 1.0 in the third and fourth factors. According to the Correlation of the factors, the first factor is correlated positively with itself and third factor is correlated positively and most densely with the fourth factor, while the second factor is correlated negatively with the third factor, and the third factor is also negatively correlated with the third factor. The result that the factors are correlated with each other in this way can be interpreted that a judgment can be made about other two factors based on their results.

The results of factor analysis which shows to what extend the effectiveness criteria determined for "policy-strategy level", the fourth organizational level in an university, are associated with the aspects of organizational effective- 
Table 7: Factor analysis on the aspects of organizational effectiveness at university group-divisional level

\begin{tabular}{|c|c|c|c|c|c|}
\hline \multirow[t]{2}{*}{ Aspects } & \multirow[t]{2}{*}{ Items } & \multicolumn{4}{|c|}{ Factors } \\
\hline & & Factor 1 & Factor 2 & Factor 3 & Factor 4 \\
\hline \multirow[t]{16}{*}{ Integration } & 20 & .84879 & .35967 & .15829 & .12567 \\
\hline & 19 & .81949 & .39248 & .10379 & .15745 \\
\hline & 25 & .81653 & .37590 & .11990 & .20664 \\
\hline & 34 & .80319 & .38521 & .19550 & .15322 \\
\hline & 26 & .78352 & .46293 & .14609 & .20662 \\
\hline & 12 & .73729 & .31607 & .31569 & .12497 \\
\hline & 27 & .70702 & .47253 & .29412 & .02802 \\
\hline & 35 & .66590 & .49748 & 26779 & .08624 \\
\hline & 32 & .64985 & .51878 & .31690 & .08091 \\
\hline & 14 & .60425 & .55405 & .17479 & .21935 \\
\hline & 29 & .54990 & .39551 & .42850 & .18300 \\
\hline & 16 & .54366 & .52772 & .32824 & .10919 \\
\hline & 15 & .53069 & .46807 & .30666 & .21862 \\
\hline & 24 & .51472 & .38095 & .08513 & .48428 \\
\hline & 13 & .46979 & .29859 & .27203 & .36973 \\
\hline & 18 & .44676 & .39736 & .37641 & .14012 \\
\hline \multirow[t]{8}{*}{ Goal attainment } & 8 & .14478 & .83771 & .26439 & .16226 \\
\hline & 22 & .39184 & .77485 & .14144 & .13656 \\
\hline & 21 & .32124 & .74492 & .28280 & -.05104 \\
\hline & 33 & .29303 & .73893 & .31061 & .11400 \\
\hline & 9 & .25062 & .67821 & .44692 & .13015 \\
\hline & 11 & .37836 & .58961 & .29500 & .05095 \\
\hline & 31 & .50720 & .56280 & .30357 & .13491 \\
\hline & 10 & .42329 & .54476 & .38694 & .21929 \\
\hline \multirow[t]{8}{*}{ Creating and sustaining the values system } & 6 & .34544 & .24759 & .76210 & .00436 \\
\hline & 3 & .30533 & 13512 & .73849 & .18027 \\
\hline & 1 & .31512 & .10200 & .71864 & .19367 \\
\hline & 7 & .38075 & .25846 & .71640 & .07187 \\
\hline & 4 & .32004 & .38202 & .70309 & .07865 \\
\hline & 2 & .13055 & .24350 & .69449 & .21657 \\
\hline & 5 & .22676 & .47370 & .61556 & .13378 \\
\hline & 17 & .29280 & .41358 & .53239 & .13807 \\
\hline \multirow[t]{7}{*}{ Adaptation } & 28 & -.00953 & .20736 & .08797 & .76926 \\
\hline & 37 & .13675 & -.02569 & .19120 & .67719 \\
\hline & 36 & -.10671 & .30377 & .22323 & .63268 \\
\hline & 30 & .41596 & .34536 & .12284 & .60820 \\
\hline & 23 & .40688 & .26031 & .03913 & .51466 \\
\hline & 38 & .16555 & .33716 & .43632 & .50039 \\
\hline & (\%) & 42.4 & 4.9 & 4.0 & 4.0 \\
\hline Eigen & alues & 19.9 & 1.8 & 1.5 & 1.5 \\
\hline
\end{tabular}

Table 8: Factor transformation matrix at university group-divisional level

\begin{tabular}{lrrrr}
\hline & Factor 1 & Factor 2 & Factor 3 & Factor 4 \\
\hline Factor 1 & .66402 & .50665 & .48289 & .26307 \\
Factor 2 & .38517 & .03455 & -.80802 & .44447 \\
Factor 3 & -.51070 & .03216 & .21543 & .83171 \\
Factor 4 & .38718 & -.86086 & .25982 & .20373 \\
\hline
\end{tabular}

ness, and the distribution of items by aspects are given in Table 9 and Table 10.

As it can be seen in the table, effectiveness criteria determined at university policy-strategy level are grouped in five factors. This result differs from the results of previous researches about the policy-strategy level which is one of the levels in a university (Cammock et al. 1995; Hardy 1991; Hitt 1988). In said researches, policy-strategy level has four aspects just like other levels. However, in this research, a fifth aspect has been determined. This finding supports the views that there could be other aspects and criteria of effectiveness at policy-strategy level in universities (Grasso 1994; Chapman 1993; Cameron and Tschirhart 1992). This fifth aspect is called as "fundraising strategies" because it includes items 
Table 9: Factor analysis on the aspects of organizational effectiveness at policy-strategy level

\begin{tabular}{|c|c|c|c|c|c|c|}
\hline \multirow[t]{2}{*}{ Aspects } & \multirow[t]{2}{*}{ Items } & \multicolumn{5}{|c|}{ Factors } \\
\hline & & Factor 1 & Factor 2 & Factor 3 & Factor 4 & Factor 5 \\
\hline \multirow[t]{29}{*}{ Adaptation } & 17 & .78033 & .22606 & .13933 & .15037 & .12476 \\
\hline & 25 & .75728 & .35363 & .25514 & .05639 & .01142 \\
\hline & 19 & .73472 & .43140 & .11277 & .12813 & .13502 \\
\hline & 69 & .73431 & .12301 & .15579 & .18489 & -.01778 \\
\hline & 11 & .72999 & .25500 & .05538 & 16294 & .34035 \\
\hline & 34 & .72719 & .30094 & .12708 & .22442 & .00930 \\
\hline & 29 & .72437 & .32859 & .20281 & .10698 & .06917 \\
\hline & 30 & .72097 & .24894 & .20326 & -.07015 & .06212 \\
\hline & 24 & .71529 & .31578 & .20023 & .09737 & -.05285 \\
\hline & 9 & .70606 & .35613 & .00406 & .15494 & .24001 \\
\hline & 33 & .70600 & .43306 & .12044 & .16154 & .00338 \\
\hline & 21 & .70391 & .27275 & .22717 & .12286 & .01898 \\
\hline & 32 & .69879 & .46085 & .21821 & .16910 & .07079 \\
\hline & 31 & .69225 & .27333 & .09097 & .39078 & .19731 \\
\hline & 8 & .68580 & .29747 & .02557 & .31273 & .24638 \\
\hline & 20 & .67925 & .40118 & .24511 & .07062 & -.03752 \\
\hline & 14 & .67765 & .22119 & 19607 & .12630 & .24252 \\
\hline & 18 & .67314 & .28594 & .10880 & .36691 & .25547 \\
\hline & 13 & .66525 & .25847 & .26248 & .00006 & .05051 \\
\hline & 28 & .65936 & .17417 & .32494 & .24833 & -.13257 \\
\hline & 16 & .64082 & .13419 & .29504 & .23581 & .12299 \\
\hline & 26 & .63260 & .14531 & .25110 & .15516 & .19748 \\
\hline & 6 & .62985 & .37110 & .03050 & -.00207 & .24530 \\
\hline & 3 & .58900 & .42784 & .17813 & .07346 & .19808 \\
\hline & 27 & .58552 & .41001 & .34250 & -.11384 & .07045 \\
\hline & 15 & .56988 & .23830 & .41077 & .24236 & .16726 \\
\hline & 1 & .55732 & .25920 & .24705 & -.13576 & .40956 \\
\hline & 5 & .54733 & .25570 & -.00645 & .09335 & .43229 \\
\hline & 2 & .52285 & .36709 & .08300 & .06591 & .39725 \\
\hline \multirow[t]{23}{*}{ Goal attainment } & 55 & .31546 & .69739 & .31067 & .16777 & .10868 \\
\hline & 67 & .39079 & .69309 & .16333 & .30842 & .10974 \\
\hline & 49 & .38527 & .68948 & .27416 & .26633 & .17445 \\
\hline & 22 & .48878 & .67017 & .12484 & .23915 & .09687 \\
\hline & 48 & .38293 & .66510 & .22445 & .32797 & .16697 \\
\hline & 47 & .38809 & .65176 & .13183 & .33661 & .24418 \\
\hline & 56 & .44636 & .63483 & .43135 & .11502 & .04571 \\
\hline & 46 & .41209 & .63475 & .26518 & .18306 & .13075 \\
\hline & 60 & .38786 & .62124 & .25141 & .03576 & .27874 \\
\hline & 42 & .33373 & .62045 & .35060 & .08656 & .07969 \\
\hline & 64 & .36087 & .60182 & .43855 & .30090 & .08839 \\
\hline & 45 & .40857 & .59268 & .43960 & .18615 & -.03057 \\
\hline & 36 & .40657 & .58830 & .36776 & .36585 & .12569 \\
\hline & 43 & .45265 & .58827 & .25608 & .19979 & .09056 \\
\hline & 35 & .38169 & .56879 & .22421 & .38169 & .29081 \\
\hline & 54 & .31606 & .56563 & .21234 & .41025 & .13848 \\
\hline & 51 & .33469 & .56370 & .43970 & -.08911 & .22157 \\
\hline & 68 & .45315 & .55505 & .42792 & .17448 & .01516 \\
\hline & 72 & .43514 & .54775 & .41536 & .14796 & .10271 \\
\hline & 58 & .33086 & .54577 & .43971 & .16055 & .09883 \\
\hline & 57 & .39194 & .53798 & .40041 & .02184 & .21426 \\
\hline & 40 & .43124 & .51448 & .41569 & -.02645 & .19323 \\
\hline & 73 & .43303 & .50386 & .44781 & .20573 & .22951 \\
\hline \multirow[t]{7}{*}{ Integration } & 70 & 14993 & .24272 & .75453 & .13823 & .04423 \\
\hline & 38 & .12516 & .25165 & .75446 & .04881 & .19619 \\
\hline & 10 & .17091 & .33364 & .75265 & .09810 & .14364 \\
\hline & 37 & .05457 & .21776 & .72685 & .06860 & .09916 \\
\hline & 59 & .35413 & .31525 & .72624 & .00478 & .19560 \\
\hline & 23 & .09390 & .38768 & .72072 & .11248 & .15984 \\
\hline & 41 & -.00506 & .22876 & .68536 & -.08350 & -.07658 \\
\hline
\end{tabular}


Table 9: Contd....

\begin{tabular}{|c|c|c|c|c|c|c|}
\hline \multirow[t]{2}{*}{ Aspects } & \multirow[t]{2}{*}{ Items } & \multicolumn{5}{|c|}{ Factors } \\
\hline & & Factor 1 & Factor 2 & Factor 3 & Factor 4 & Factor 5 \\
\hline \multirow{10}{*}{$\begin{array}{l}\text { Creating and sustaining } \\
\text { the values system }\end{array}$} & 50 & .40765 & .33010 & .66198 & .23139 & .08046 \\
\hline & 71 & .20918 & .33565 & .62153 & .37758 & -.01529 \\
\hline & 65 & .15289 & .28492 & .52297 & .49951 & .18593 \\
\hline & 63 & .35109 & .46046 & .50106 & .07747 & .27165 \\
\hline & 39 & .25333 & .36657 & .49399 & .18526 & .24647 \\
\hline & 62 & .21862 & .35525 & .44531 & .32227 & .40879 \\
\hline & 52 & .40260 & .03911 & .25774 & .70067 & .18335 \\
\hline & 66 & .11496 & .34843 & .30767 & .68841 & -.01386 \\
\hline & 7 & .52350 & .12536 & -.09211 & .54756 & .30209 \\
\hline & 12 & .41959 & .11845 & .26058 & .44612 & .03269 \\
\hline \multirow[t]{6}{*}{ Fundraising strategies } & 53 & .36475 & .11699 & .23779 & .13888 & .76141 \\
\hline & 61 & .16350 & .24891 & .36626 & .16443 & .65302 \\
\hline & 4 & .51548 & .20136 & -.03377 & .08193 & .54315 \\
\hline & 44 & .36115 & .38635 & .00291 & .24195 & .41334 \\
\hline & $(\%)$ & 54.2 & 6.6 & 2.6 & 2.6 & 2.1 \\
\hline & alues & 39.5 & 4.8 & 1.9 & 1.8 & 1.5 \\
\hline
\end{tabular}

such as the university's attitude towards strategic planning, economic self-sufficiency, offering online facilities, and clarity of accommodation and nutrition policies (Dong 2000).

In the factor analysis on effectiveness criteria at university policy-strategy level, the items above .41 are taken into account. According to Tables 10 and 11, items about the first aspect (adaptation), the second aspect (goal attainment), third aspect (integration) and fourth aspect (creating and sustaining the values system) of organizational effectiveness are covered under the first factor, second factor, third factor and fourth factor, respectively. Percentage of variance of these items are calculated as follows; $52.4 \%$ in the first factor, $4.9 \%$ in the second factor, and $4.0 \%$ in the third and fourth factors. Eigen values are found as follows; 19.9 in the first factor, 1.8 in the second factor, and 1.0 in the third and fourth factors. Under the fifth factor, the factors about a fifth aspect (fundraising strategies) which are determined as a result of research are covered. Percentage of variance of these items are calculated as follows; $54.2 \%$ in the first factor,
$6.6 \%$ in the second factor, $2.6 \%$ in the third factor and 2,1\% in the fourth factor. Eigenvalues are found as follows; 39.5 in the first factor, 4.8 in the second factor, and 1.9 in the third factor, 1.8 in the fourth factor, and 1.5 in the fifth factor.

Factor analyses of this research indicated five factors of administrational effectiveness. This result encouraged previous studies about the eight parameters of administrational effectiveness (Analoui 2007).

According to Correlation of the factors, the first factor is correlated positively with itself, second factor is correlated positively with the third factor, and third factor is correlated positively with fourth factor, and the fourth factor is correlated positively with the third factor, while the fifth factor is correlated positively and most densely with itself.

Measuring the effectiveness of relational efforts is imperative for determining future administrative performance (Padmavathy et al. 2012) but limited research has been conducted to evaluate its effectiveness (Mithas et al. 2005; Chen et al. 2009). In addition, most of the controver-

Table 10: Factor transformation matrix at policy-strategy level

\begin{tabular}{|c|c|c|c|c|c|}
\hline & Factor 1 & Factor 2 & Factor 3 & Factor 4 & Factor 5 \\
\hline Factor 1 & .66020 & .57009 & .37687 & .23795 & .20119 \\
\hline Factor 2 & -.63981 & .28676 & .70334 & .05954 & -.10093 \\
\hline Factor 3 & .04423 & -.51722 & .17974 & .83558 & -.00449 \\
\hline Factor 4 & .37542 & -.52054 & .55678 & -.46320 & -.25207 \\
\hline Factor 5 & -.10898 & -.23300 & .14484 & -.16455 & .94116 \\
\hline
\end{tabular}


sies around organizational effectiveness research is due to the fact that a lot of the research assumes that organizational effectiveness is a single variable. More recent approaches have seen an increasing use of multi-dimensional conceptions (Jacob and Shari 2012; Farahbakhsh 2007). The results of this research support these approaches.

\section{CONCLUSION}

The clear organizational characteristics of higher education institutions pose special problems for researchers in selecting the criteria of organizational effectiveness and evaluating such criteria. By having this, just like the problems related to the concept of organizational effectiveness, the characteristics of institutions operate as obstacles in evaluating the effectiveness of universities and higher education institutions in an empirical manner. In fact, no research has been made in the literature to measure the administrative effectiveness in higher education institutions directly.

Administrative effectiveness cannot be measured by a single aspect in order to be useful and operational. The results indicated that administrative effectiveness can be increased through organizational levels. The results also revealed that it is inevitable to associate these levels with the aspects of organizational effectiveness.

Therefore, it is possible to determine and evaluate administrative effectiveness in university organizations through administrative effectiveness criteria that are developed by synthesizing four levels in universities and aspects of organizational effectiveness. It is believed that evaluation tool for administrative effectiveness which is developed to that end and recommended below can be used in administrative effectiveness researches and studies at universities.

\section{RECOMMENDATIONS}

1. The efforts to evaluate administrative effectiveness in a university must be conducted with some certain criteria. The recommended questionnaire (see appendix 1) as a data collection tool could be useful and utilized for this kind of research.

2. This research could be repeated on a more extensive or different sample to improve the effectiveness criteria.
3. By using this tool, a research can be conducted on the evaluation of administrative effectiveness in universities.

4. These tools can also be used to determine the administrative effectiveness of other educational levels.

5. This tool can be useful to make research on the administrative effectiveness of organizations other than educational institutions.

\section{REFERENCES}

Adeniyi WO, Omoteso BA 2014. Emotional intelligence and administrative effectiveness of secondary school principals in Southwestern Nigeria. International Journal of Psychology and Behavioral Sciences, 4(2): 79-85.

Adeyemi TO, Ademilua SO 2012. Conflict management strategies and administrative effectiveness in Nigerian Universities. Journal of Emerging Trends in Educational Research and Policy Studies (JETERAPS), 3(3): 368-375.

Akomolafe CO 2012. A comparative study of principals' administrative effectiveness in public and private secondary schools in Ekiti State, Nigeria. Journal of Education and Practice, 3(13): 39-45.

Amah E, Daminabo-Weje M, Dosunmu R 2013. Size and organizational effectiveness: maintaining a balance. Advances in Management and Applied Economics, 3(5): 115-123.

Analoui F 2007. Strategic Human Resource Management. London: Thompson Learning.

Bao C 2009. Comparison of public and private sector managerial effectiveness in China: A three-parameter approach. Journal of Management Development, 28(6): 533-41.

Cameron K 1978. Measuring organizational effectiveness in institutions of higher education. Administrative Science Quarterly, 23: 604-632.

Cameron K, Tschirhart M 1992. Postindustrial environment and organizational effectiveness in coolleges and universities. Journal of Higher Education, 63(1): 87-108.

Cammock P, Nilakant V, Dakin S 1995. Developing a lay model of administrative effectiveness: A social constructionist perspective. Journal of Administration Studies, 32(4): 443- 473.

Chapman J 1993. Leadership, administration and the effectiveness of schooling: A response to Mr Gradgrind. Journal of Educational Administration, 31(4): 4-18.

Chen JS, Yen HJR, Li EY, Ching RKH, Measuring CRM 2009. Measuring CRM effectiveness: onstruct development, validation and application of a processoriented model. Total Quality Management \& Business Excellence, 20(3): 283-99.

Drucker, PF 1994. Etkin Yöneticilik, Istanbul: Eti Kitaplari.

Farahbakhsh S 2007. Managerial effectiveness in educational administration: Concepts and perspectives. Management in Education, 21(2): 33-36. 
Garza CE 1991. Studying the natives on the shop floor. Business Week, 30: 74-78.

Gibson JL, Ivancevich JM, J.H. Donnelly JH JR 1994. Organization: Behavior, Structure, Processes. R.D. Boston, Sidney: Irwin, Inc.

Grasso AJ 1994. Administration style, job satisfaction, and service effectiveness. Administration in Social Work, 18(4): 89-105.

Hardy C 1991. Configuration and strategy making in universities. Journal of Higher Education, 62(4): 363-393.

Hitt MA 1998. The measuring of organizational effectiveness: Multiple domains and constituencies. MIR (Administration of Institutional Review), 28(2): 2840.

Hofler D 2010. Contigency approach to management. Journal of Business Research, 63(7): 763-771.

Hoy WK, Miskel GC 1987. Educational Administration: Theory, Research andPractice. $3^{\text {rd }}$ Edition, New York: Random House, Inc.

Jacob NE, Shari B 2012. Organizational effectiveness in educational institutions. International Journal of Management Research and Reviews. 2(12): 20152025.

Lovelady L 1994. Change strategies and the use of the OD consultants to facilitate change: Part I. Leader- ship and Organizational Development Journal, 5(2): 3-5.

Miles MB 1979. Macro Organizational Behavior. Santa Monica, CA: Inc. unknown.

Miller JG 1978. Living Systems. New York: McGrawHill, Inc.

Mithas S, Krishnan MS, Fornell C 2005. Why do customer relationship management applications affect customer satisfaction. Journal of Marketing, 69(4): 201-9.

Padmavathy C et al. 2012. Measuring effectiveness of customer relationship management in Indian retail banks. Sivakumar International Journal of Bank Marketing, 30(4): 246-266

Rashford N, Coghlan D 1987. Enhancing human involvement in organizations -A paradigm for participation. Leadership \& Organization Development Journal, 8(1): 17-21.

Rashford N, Coghlan D 1992. Effective administration through organizational levels. Journal of Educational Administration, 30(4): 63-72.

Stewart R 1989. Studies of administrative jobs and behaviour: The ways forward. Journal of Administration Studies, 26(1): 1-10.

Wang J 2011. Understanding managerial effectiveness: A Chinese perspective. Journal of European Industrial Training, 35(1): 6-23. 